\title{
THE ASSESSMENT OF WEAR METAL CONCENTRATION IN ENGINE OILS ORIGINATING FROM AGRICULTURAL TRACTORS IN THE ASPECT OF THEIR OPERATIONAL PROPERTIES
}

\author{
Grzegorz ZAJĄC ${ }^{\mathbf{1}}$, Artur WOLAK ${ }^{\mathbf{2}}$, Wojciech GOLĘBIOWSKI ${ }^{\mathbf{1}}$, Jan VRABEL ${ }^{3}$ \\ ${ }^{1}$ University of Life Sciences in Lublin, POLAND \\ ${ }^{2}$ Cracow University of Economics, POLAND \\ ${ }^{3}$ University of Zilina, SLOVAKIA \\ E-mail of corresponding author: artur.wolak@uek.krakow.pl
}

Keywords: engine oil, farm machinery management, agricultural tractors, wear metal concentration, oilchange interval

\begin{abstract}
One of the paths leading to the development of sustainable agriculture is to reduce the amount of energy lost during agricultural production. This can be accomplished through proper farm machinery management. The engine oil obtained at the end of the oil-change interval may be a valuable source of information on the processes and causes of wear of the tribological systems of the engine. This paper presents the results of studies on the wear metal concentration $(\mathrm{Pb}, \mathrm{Cr}, \mathrm{Ni}, \mathrm{Fe})$ in engine oils, taken from selected agricultural tractors, which were subject to replacement within the timeframe specified in the maintenance schedule. The statistical analysis of the test results has not revealed any statistically significant differences in the concentrations of the investigated elements in the used engine oils, depending on the mileage. Nevertheless, the calculated coefficients of correlation indicate a positive, weak correlation between the analysed elements and the engine oil consumption processes under operating conditions.
\end{abstract}

\section{INTRODUCTION}

One of the paths leading to the development of sustainable agriculture is to reduce the energy expenditure. Therefore, tractors and farm machines should be as much efficient as possible, both in terms of their power units and their power trains (Bietresato et al., 2015). Tractors and farm machines are characterized by a great variety of types and constructions, extended life span, and a high variability of working conditions compared to other vehicles. Such complex operating conditions are strongly influenced by the unique nature of agricultural production: tractors are used in variable weather conditions, they are operated with varying intensity during the year, they are associated with seasonal work and are driven mainly off-road.

Non-operational factors, such as technical preparation of tractor operators as well as the quality of maintenance and repair facilities are also important (Tomczyk, 2009, 2012). All of these factors affect the specific (depending on the tractor type) wear processes including engine oil consumption.

One of the basic tasks that must be undertaken to protect tractors from adverse operating conditions is to carry out, on a regular basis, the replacement of parts and consumables (Buchwald and Staszak, 2013; Rybacki and Buchwald, 2013). Lubricating oil, without which the engine would not be able to function properly, can operate in the engine as long as it performs its tasks properly (Wolak and Zając, 2017). Delays in servicing or replacing the consumables with improper substitutes can result in undesirable machine failures (Osuch et al., 2016).

According to research (Jósko and Kołodziejski, 2008), one of the fundamental mistakes made by users of agricultural tractors is the failure to keep oil change periods. Another problem is the poor quality of technical services provided by local garages, including the use of improper oil. The engine oil obtained at the end of the oil-change interval 
may be a valuable source of diagnostic information. The presence of impurities in the oil depends mainly on the intensity of the wear process, and - to a small extent - it might result from a direct contact with the fuel or the cooling fluid. The analysis of the metal content of the used engine oil can provide information on the wear range of the metal parts of the engine. This paper presents the results of studies on engine oils (collected from selected agricultural tractors), which were subject to replacement within the timeframe specified in the maintenance schedule. The major parameter of the evaluation of oils was the concentration of selected heavy metals $(\mathrm{Pb}, \mathrm{Cr}, \mathrm{Ni}, \mathrm{Fe})$. Within the scope of research tasks, the analyzed engine oil samples were classified based on the empirical data obtained. The analysis was partly conducted with the use of selected tools for exploring and grouping data: agglomeration method (with a single bond algorithm) and the Euclidean distance formula.

\section{MATERIAL AND METHODS}

The test material consisted of engine oil samples obtained at the end of the oil-change interval. The samples were collected from various agricultural tractors (of different manufacturers and power classes). The oil samples were qualified based on the oilchange dates recommended by the tractor manufacturers. They were obtained from service companies dealing with the repair of agricultural tractors and individual farmers from the area of the Lublin Voivodeship.

Due to the fact that the structure of the inspection plan and the replacement of oil in agricultural tractors is different in terms of frequency for each type of tractor, it was decided to put the collected oil samples into 4 groups, according to the tractors' operating history.

A1-3 oils were collected from tractors of up to $100 \mathrm{mth}, \mathrm{B} 1-7$ oils were from tractors with a mileage of 100-400 mth, C1-7 oils were collected from tractors with a mileage of 400-1000 mth, and D1-4 were collected from the tractors with a mileage of over 1000 mth.

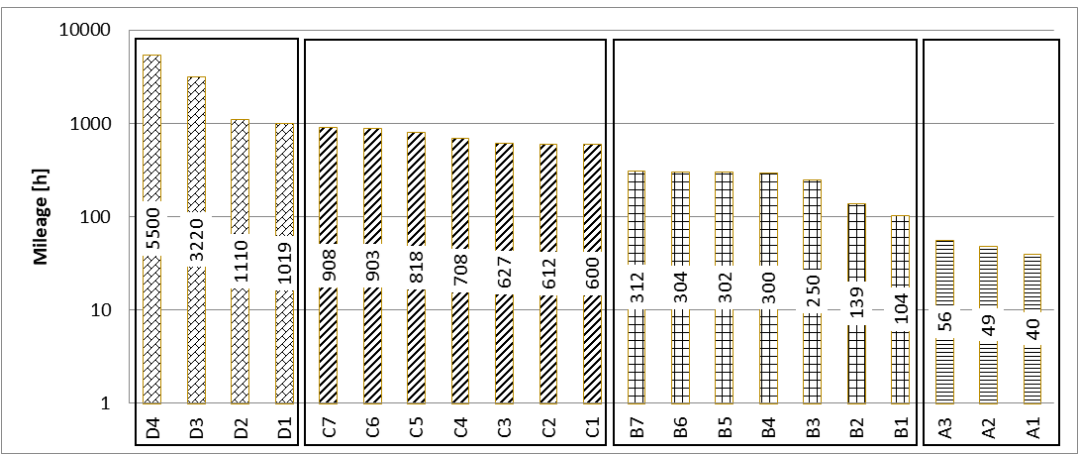

Fig. 1. The number of hours operated by each agricultural tractor

The study was conducted using the XOS HDMaxine analyzer. This is a multi-element tool for determining trace elements in liquid samples on a hydrocarbon matrix, based on high resolution X-ray fluorescence (High Definition X-ray Fluorescence- HDXRF). The contents of the wear elements, i.e. $\mathrm{Pb}, \mathrm{Cr}$, $\mathrm{Ni}$ and $\mathrm{Fe}$, were determined using the XDMaxine apparatus. All of the analyzes were performed in triplicate for each sample.

The results obtained were statistically analyzed using the STATISTICA software program. To investigate the dependence of the tractors' operating history (including heavy metals), scatter plots with regression line and correlation coefficient were applied 
in the analysis of the used engine oils. The research task was to first classify the examined samples so as to extract relatively uniform groups, representing samples with similar concentrations of wear metals.

Of the many methods available for cluster analysis, the agglomeration method was selected (hierarchical classification), in which algorithms are used to group objects in increasing clusters using the selected distance measure (Euclidean). In the basic version, the agglomeration method consists of the following steps: a definition of grouping objects (or cases) and their characteristics, a definition of distance metrics between objects, a selection of the algorithm to calculate distances between clusters.

The last of the necessary steps to allow the analysis of clustering by agglomeration method is to choose an algorithm with which the distance between object classes can be measured. The commonly applied single bond method, also known as the nearest neighbor method, was used in the study. In this method, the distance between the two clusters is determined by the distance between the two nearest neighbors belonging to different clusters.

\section{RESULTS AND DISCUSSION}

The results of the determinations of heavy metals in the used engine oils are shown in Figure 2. The obtained data indicate that the concentrations of metals were quite different depending on the type of machine, type of oil, and mileage.
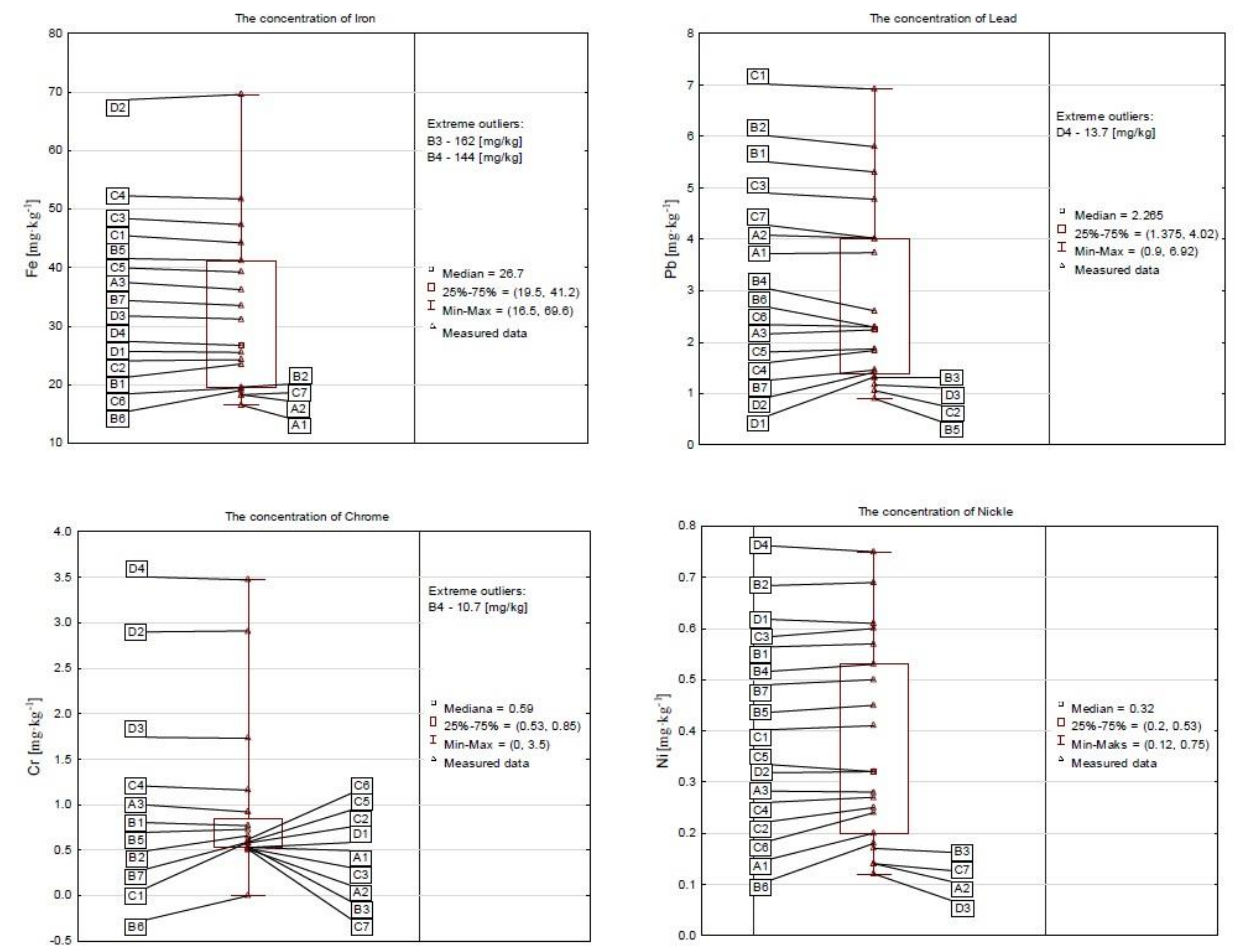

Fig 2. The concentrations of metals

The average lead concentration in the samples was $3.34 \mathrm{mg} \cdot \mathrm{kg}^{-1}$. The lowest value was recorded for sample B5 $\left(0.9 \mathrm{mg} \cdot \mathrm{kg}^{-1}\right)$, and the highest for sample D4 $\left(13.71 \mathrm{mg} \cdot \mathrm{kg}^{-1}\right)$. Such high $\mathrm{Pb}$ concentration in sample $\mathrm{D} 4$ resulted in a very high coefficient of variation, which amounted to $88 \%$. The concentration of nickel in the samples tested was on the level from 0.12 to $0.75 \mathrm{mg} \cdot \mathrm{kg}^{-1}$ (on average: $0.37 \mathrm{mg} \cdot \mathrm{kg}^{-1}$ ). The variability of concentration was characterized by a high coefficient of variation of almost $53 \%$. The 
chromium concentration in the samples tested fluctuated from 0 for sample B6 up to $10.7 \mathrm{mg} \cdot \mathrm{kg}^{-1}$ for sample B4. The average concentration was on the level of $1.39 \mathrm{mg} \cdot \mathrm{kg}^{-}$ 1. As a result of a very high concentration of this element in one of the samples, the coefficient of variation was as high as $164 \%$. In the samples tested, the lowest iron concentration was found in sample A1 $\left(16.5 \mathrm{mg} \cdot \mathrm{kg}^{-1}\right)$ and the highest in sample B3 (162 $\mathrm{mg} \cdot \mathrm{kg}^{-1}$ ). Due to a very high Fe concentration in two samples (exceeding $100 \mathrm{mg} \cdot \mathrm{kg}^{-1}$ ), the coefficient of variation was at $90 \%$.

The second part of the empirical analysis focuses on identifying the similarities and differences between the analyzed oils from the perspective of the selected criteria (wear metals). The results presented in the form of dendrograms (hierarchical method) are shown in Figure 3.

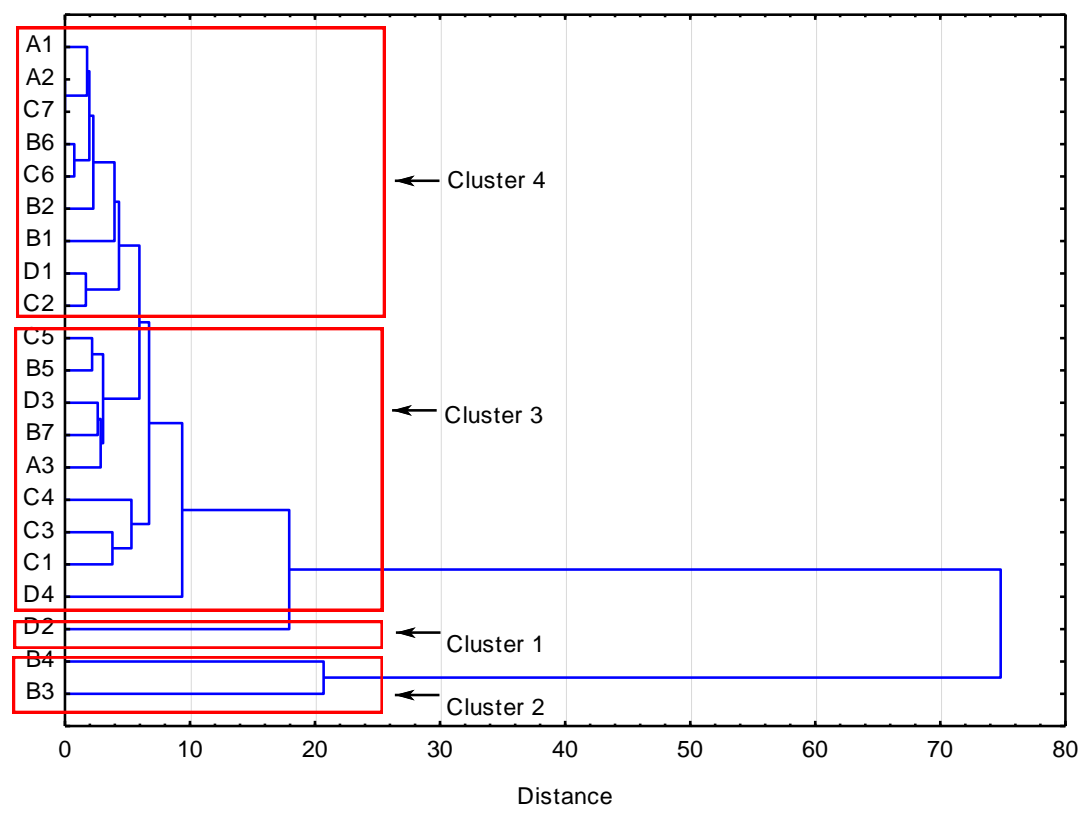

Fig 3. Dendrogram (Euclidean distance)

As a result of the conducted classification, 4 groups of engine oils were identified. The groups were called: cluster 1, 2, 3 and 4 . The first group contains only one oil (D2), the second one - two (B3 and B4), the third group - 9 oils (A1, A2, C7, B6, C6, B2, B1, D1, C2), and the fourth one - another 9 oils (C5, B5, D3, B7, A3, C4, C3, C1, D4). Cluster analysis is used to identify groups in which oils are most similar to each other in terms of the analyzed wear metals. These are: A2 and C7, B6 and C6, plus D1 and C2, respectively. The most alienated oils are the ones belonging to clusters 1 and 2 .

Comparing the received clusters with the groups formed on the basis of mth, it can be concluded that the mileage does not affect the concentrations of $\mathrm{Fe}, \mathrm{Pb}, \mathrm{Cr}$ and $\mathrm{Ni}$. To further verify whether there is a statistical relationship between the mileage and the concentrations of wear metals, scatter plots with regression line and correlation coefficient were used. The analyzed oils, from the perspective of the mileage (expressed in mth), are strongly asymmetrical; that is why, the logarithms of mileage were applied to make scatter plots and to check correlation. 

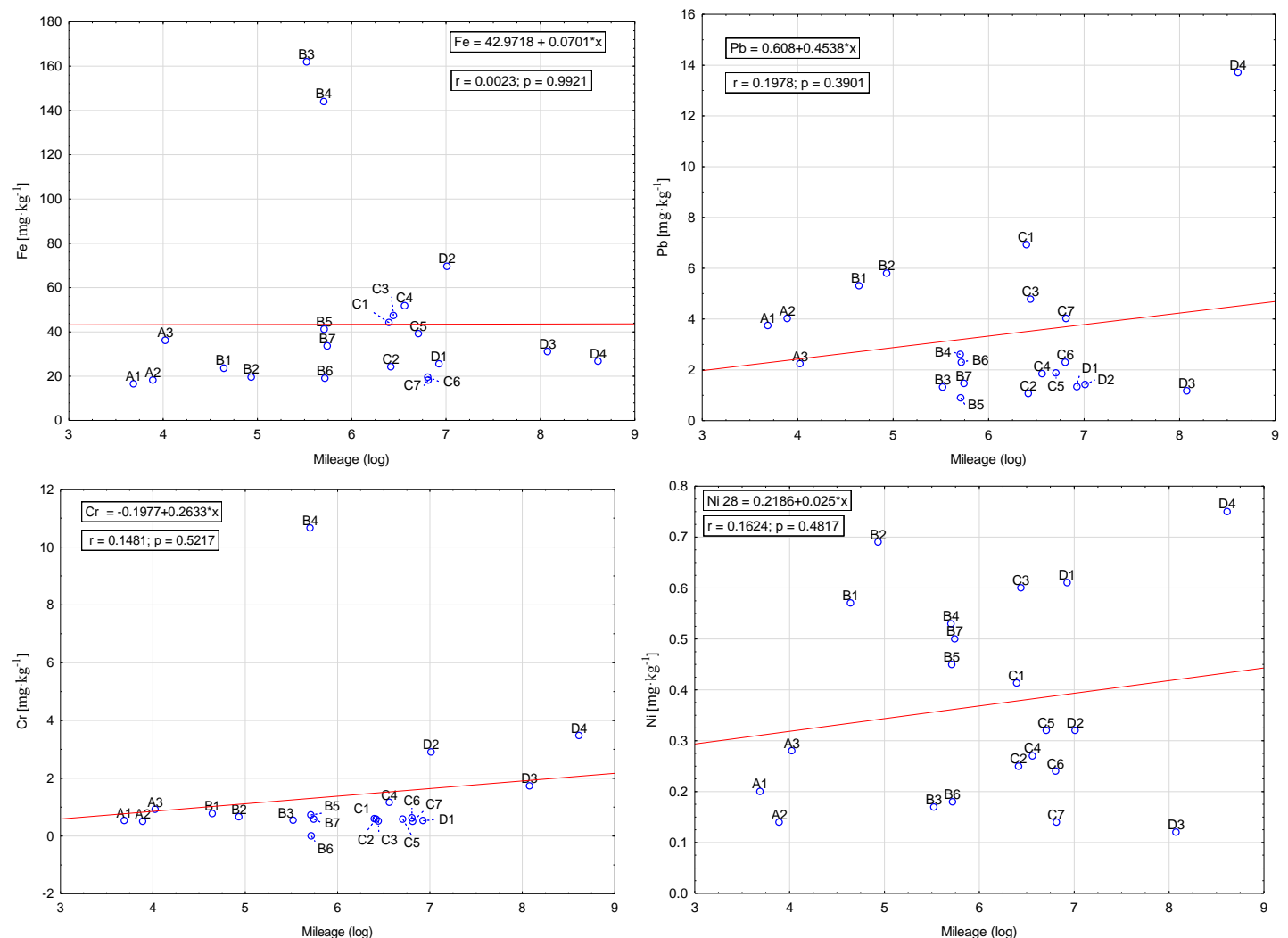

Fig 4. Scatter plots with regression line and correlation coefficient

When analyzing the received significance levels $(0.9921 ; 0.3901 ; 0.5217$ and 0.4817$)$, it was found that all of them are above the limit value $(0.05)$ and therefore they should be deemed statistically insignificant. It may be then concluded that there are no statistically significant differences between the tractor mileage (log Mth) and the concentration levels of wear metals. The correlation coefficients indicate that in all four cases a positive correlation was obtained, confirming that an increase in the analyzed chemical elements is related to the process of wear and tear during operation. The highest correlation coefficient was obtained for $\mathrm{Pb}(\mathrm{r}=0.2)$. According to J. Guilford's terminology, this is indeed a weak correlation. Very slight (positive) correlation was obtained for $\mathrm{Fe}(\mathrm{r}=0.002)$. Moreover, scatter plots with regression lines and correlation coefficients indicate strong outliers. These are the following engine oil samples: B3 and B4 (Fe), B4 $(\mathrm{Cr})$, and D4 (Pb).

\section{CONCLUSIONS}

Mistakes in technical operation of agricultural machinery, especially the ones affecting combustion engines, may lead to accelerated wear of their components, which in turn oftentimes translates into higher costs of necessary repairs (Osuch et al., 2016). One of the most essential tasks that must be undertaken to protect tractors from adverse operating conditions is to carry out the replacement of consumables at regular intervals. The engine oil obtained at the end of the oil-change interval may be a valuable source of information on the processes and causes of wear of the tribological systems of the engine. The applied XRF method, unlike other methods, makes it easy to determine the concentrations of elements in a very wide measuring range (Pouzar et al., 2001; Zając et al., 2015). 
Based on the research findings and the discussion, the following conclusions have been made:

1. The obtained correlation coefficients confirm a weak, positive correlation between the concentrations of the analyzed wear metals and the tractors' mileage (expressed in $\mathrm{mth}$ ). Consequently, the complex operating conditions of agricultural tractor engines may lead to unpredictable changes in lubricating oils.

2. The wear metals examined $(\mathrm{Fe}, \mathrm{Pb}, \mathrm{Cr}, \mathrm{Ni})$ show a large variety of concentrations. The highest coefficient of variation was calculated for $\mathrm{Cr}(164 \%)$, then for $\mathrm{Fe}$ $(90 \%)$, and $\mathrm{Pb}(88 \%)$. The lowest coefficient of variation was determined for $\mathrm{Ni}$ (53\%). Therefore, it is difficult to accurately predict the concentrations of the analyzed wear metals in engine oils.

3. Statistical analysis of the study results did not show any statistically significant differences in the concentrations of the analyzed wear metals found in the used engine oils, depending on the mileage. Hence, when evaluating the concentrations of wear metals in engine oil, each element should be assessed individually and full attention should be paid to any noticeable increases in the concentrations.

4. As a result of the use of the agglomeration method (cluster analysis), 4 groups were identified in which engine oils are most similar to each other in terms of the concentrations of the analyzed wear metals. These are: A2 and C7, B6 and C6, plus D1 and C2, respectively.

\section{REFERENCES}

Bietresato, M., Calcante, A., Mazzetto, F. (2015). A neural network approach for indirectly estimating farm tractors engine performances. Fuel 143, 144-154.

Buchwald, T., Staszak, Ż. (2013). Analiza realizacji przeglądów technicznych ciągników rolniczych. Inż. Rol. 17.

Jósko, M., Kołodziejski, D. (2008). Selected exploitation problems of agricultural vehicles in the scope of their servicing. J. Res. Appl. Agric. Eng. 53 (2), 5-7.

Osuch, A., Rybacki, P., Osuch, E., Przygodziński, P., Ratajczak, J. (2016). Analysis of schedule and execution of technical inspections of agricultural tractors. Nauka Przyr TechnolV 10 (4).

Pouzar, M., Černohorský, T., Krejčová, A. (2001). Determination of metals in lubricating oils by Xray fluorescence spectrometry. Talanta 54 (5), 829-835.

Rybacki, P., Buchwald, T. (2013). Structure of planned technical service of agricultural tractors based on comparative research. J. Res. Appl. Agric. Eng. 58 (2), 141-144.

Tomczyk, W. (2009). Obsługi techniczne w procesie odnowy i utrzymania maszyn i urządzeń rolniczych. Inż. Rol. 13, 301-307.

Tomczyk, W. (2012). Metoda modelowania zestawu obsług technicznych maszyn i urządzeń rolniczych. Inż. Rol. 16, 319-325.

Wolak, A., Zając, G. (2017). The kinetics of changes in kinematic viscosity of engine oils under similar operating conditions. Eksploat. Niezawodn. - Maint. Reliab. 19 (2), 260-267.

Zając, G., Szyszlak-Bargłowicz, J., Słowik, T., Kuranc, A., Kamińska, A. (2015). Designation of Chosen Heavy Metals in Used Engine Oils Using the XRF Method. Pol. J. Environ. Stud. 24 (5), 2277-2283. 